Abstract P-014 Table 1 Malfunctions by catheter and outcome. Abstract table limit requires category 'Other'

\begin{tabular}{lllll}
\hline Catheter & Death & Injury & No Adverse Event & Total \\
\hline 3 MAX & 1 & 45 & 322 & 368 \\
5 MAX & 0 & 9 & 374 & 383 \\
ACE 60 & 0 & 1 & 57 & 58 \\
ACE 64 & 0 & 12 & 75 & 87 \\
ACE 68 & 0 & 4 & 247 & 251 \\
Jet 7 & 13 & 19 & 258 & 290 \\
Penumbra 032 & 0 & 1 & 139 & 140 \\
Penumbra 054 & 0 & 2 & 55 & 57 \\
Other & 0 & 5 & 200 & 174 \\
\hline
\end{tabular}

occurred on the back table during device preparation. Detailed descriptions of unique malfunction mechanisms for each catheter are omitted from this brief abstract but are available for presentation.

Conclusion Reperfusion catheter failures resulting in injury or death are rare. These findings suggest that current methods of FDA surveillance have effectively identified outliers.

Disclosures D. Bageac: None. B. Gershon: None. R. De Leacy: None.

\section{P-015 THE ZOOM SYSTEM DEMONSTRATES HIGHER FIRST PASS EFFECT AND FASTER REPERFUSION AS COMPARED TO A CONSECUTIVE CONTEMPORANEOUS SERIES OF ASPIRATION CATHETERS: ANALYSIS FROM A MULTICENTER RETROSPECTIVE COHORT}

${ }^{1} S$ Majidi ${ }^{*},{ }^{2}$ J Vargas, ${ }^{3} \mathrm{H}$ Hawk, ${ }^{4} S$ Nimjee, ${ }^{4} \mathrm{~A}$ Zakeri, ${ }^{5} \mathrm{M}$ Mokin, ${ }^{6} \mathrm{R}$ Kellogg, ${ }^{1} \mathrm{R}$ Deleacy, ${ }^{7} \mathrm{G}$ Cortez, ${ }^{7} \mathrm{~A}$ Aghaebrahmin, ${ }^{7} \mathrm{E}$ Sauvageau, ${ }^{7} \mathrm{R}$ Hanel, ${ }^{8} \mathrm{~A}$ Siddiqui, ${ }^{9} \mathrm{M}$ Oselkin, ${ }^{9} \mathrm{E}$ Marlin, ${ }^{2} \mathrm{~A}$ Turk, ${ }^{2} \mathrm{R}$ Turner, ${ }^{2} \mathrm{C}$ Chaudry, ${ }^{10} \mathrm{~J}$ Milburn. ${ }^{1}$ Neurosurgery, Mount Sinai Health System, New York, NY; ${ }^{2}$ Neurosurgery, Prisma Health - Upstate, Greenville, SC; ${ }^{3}$ Radiology, Erlanger Health System, Chattanooga, $T N_{;}{ }^{4}$ Neurosurgery, Ohio State University, Columbus, $\mathrm{OH} ;{ }^{5}$ Neurosurgery, University of South Florida, Tampa, FL; ${ }^{6}$ Neurosurgery, University of Virginia, Charlottesville, VA; ${ }^{7}$ Neurosurgery, Baptist Medical Center, Jacksonville, FL; ${ }^{8}$ Neurosurgery, University of Buffalo, Williamsville, NY; ${ }^{9}$ Neurosurgery, St Luke's University Health Care, Bethlehem, PA; ${ }^{10}$ Radiology, Oschner Health, New Orleans, LA

\subsection{6/neurintsurg-2021-SNIS.51}

Background Modern aspiration catheters have revolutionized thrombectomy outcomes. The Zoom System is series of catheters, with ID's of $0.045,0.055,0.071$, and 0.088 , that are advertised as being designed to support superior stroke thrombectomy performance. We aimed to preliminarily evaluate such claims by retrospectively assessing technical outcomes in a consecutive series of M1 ELVOs in which aspiration was the first line approach.

Methods We performed a retrospective multicenter analysis of consecutive ELVO patients with M1 occlusion treated within 24 hours from the time of last known well. Patients were divided into two cohorts: those in whom the Zoom 088 or 071 was the initial technology used to attempt reperfusion and those in whom any other aspiration catheter was used for initial reperfusion attempt. The primary outcome was excellent reperfusion ( $\mathrm{TICI} \geq 2 \mathrm{C}$ ) on first pass. Secondary outcomes included the rate of excellent reperfusion and successful reperfusion (TICI $\geq 2 \mathrm{~B}$ ), access to successful reperfusion time, and occurrence of downstream emboli. All data was self-adjudicated. No outside funding was provided for this analysis.
Results Total of 660 patients with acute M1 occlusion who underwent thrombectomy were identified. Zoom System catheters $(088$ or 071$)$ were used as primary aspiration catheter in 172 patients, while 488 patients were treated with other aspiration catheters (ranging from 064 to 074). The baseline mRS score, admission NIHSS score, the rate of intravenous thrombolytic therapy, symptom onset to hospital arrival, and use of anesthesia were not different between the cohorts. The primary outcome, first pass excellent reperfusion, was significantly higher in the Zoom System cohort $(51 \%$ vs $41 \%$, $\mathrm{p}=0.02)$. The rate of excellent reperfusion was significantly higher in the Zoom cohort $(68 \%$ vs $59 \%, \mathrm{p}=0.04)$, however, there was no difference in the rate of successful reperfusion (96\% vs 94\%, p=0.78). Access time to final reperfusion was significantly faster in the Zoom cohort (27 vs 35 minutes, $\mathrm{p}<.0001$ ). After adjusting for confounding factors (age, thrombectomy technique, use of secondary aspiration catheter), access time to TICI $2 \mathrm{~B}$ ( 30 vs 35 minutes, $\mathrm{p}=0.028$ ) and final recanalization ( 25 vs 31 minutes, $\mathrm{p}=0.018$ ) were significantly shorter in the Zoom System cohort.

Conclusion This retrospective, multicenter, consecutive realworld experience suggests that using Zoom 088 or 071 as primary aspiration catheter may demonstrate superior technical outcomes for M1 thrombectomy.

Disclosures S. Majidi: None. J. Vargas: 2; C; Cerenovus, Medtronic. 4; C; Truvic. H. Hawk: None. S. Nimjee: None. A. Zakeri: None. M. Mokin: 2; C; Medtronic, Cerenovus. R. Kellogg: None. R. DeLeacy: None. G. Cortez: None. A. Aghaebrahmin: None. E. Sauvageau: None. R. Hanel: 1; C; Microvention, Stryker. 2; C; Medtronic, Microvention, Stryker, Balt, Cerenovus, Q’Apel. A. Siddiqui: 2; C; Imperitive Care, Medtronic, Microvention, Penumbra, Q’Apel, Stryker. 4; C; Imperitive Care, Q’Apel, Truvic, RiSt. M. Oselkin: None. E. Marlin: None. A. Turk: 2; C; Impertive care, stryker, medtronic, penumbra, balt, cerenovus. 4; C; imperitive care. R. Turner: 2; C; Q'Apel, Cerenovus, Medtronic, Siemens. 4; C; Q’Apel. I. Chaudry: 2; C; Medtronic, Microvention, Q’Apel. 4; C; Q’Apel. J. Milburn: None.

\section{P-016 ASSOCIATION OF CEREBRAL MICROBLEEDS AND CLINICAL OUTCOMES FOLLOWING ENDOVASCULAR STROKE THERAPY}

${ }^{1} \mathrm{H}$ Saber* ${ }^{*}$, J Saver, 'V Szeder, ${ }^{1} \mathrm{M}$ Nour, ${ }^{1} \mathrm{~K}$ Khatibi, ${ }^{1} \mathrm{~L}$ Ponce Mejia, ${ }^{1} \mathrm{~S}$ Tateshima, ${ }^{3} \mathrm{G}$ Colby, ${ }^{1} \mathrm{~N}$ Kaneko, ${ }^{1} \mathrm{R}$ Jahan, ${ }^{1} \mathrm{G}$ Duckwiler, ${ }^{2} \mathrm{D}$ Liebeskind. ${ }^{1}$ Interventional Neuroradiology, UCLA, Los Angeles, CA; ${ }^{2}$ Neurology, UCLA, Los Angeles, CA; ${ }^{3}$ Neurosurgery, UCLA, Los Angeles, CA

\subsection{6/neurintsurg-2021-SNIS.52}

Introduction/Purpose Cerebral microbleeds (CMBs) are associated with the risk of hemorrhagic and ischemic stroke. We investigated the association between presence of CMBs and clinical outcomes following endovascular therapy (EVT) for emergent large vessel occlusion (ELVO) stroke.

Materials and Methods This is a retrospective analysis of consecutive adult patients undergoing EVT for an ELVO with available pre-interventional MR imaging between 2013-2019. Pretreatment GRE MRI sequences were analyzed in all patients to explore the frequency and location of prior microbleeds. Primary outcomes included post-interventional intracerebral hemorrhage $(\mathrm{ICH})$ and favorable outcome defined as functional independence with modified Rankin Scale scores of 
0 to 2 at discharge. Association of outcomes with prior CMBs was quantified using multiple logistic regression.

Results Among 155 patients included in the analysis (mean age 67.5 , SD 1.15; 56.2\% female), 20 (12.9\%) had CMBs on GRE imaging prior to EVT. Among those with CMBs, 8 $(40 \%)$ patients had strictly lobar, 4 (20\%) had mixed cortical/ subcortical, and $5(25 \%)$ patients had high burden $(>5)$ microbleeds. Older age, female sex, and presence of atrial fibrillation were significantly higher in patients with CMBs. Overall, 41 (26.4\%) developed ICH, among whom 9 (5.8\%) were symptomatic. In multivariable analysis adjusting for age, sex, presenting NIHSS, hypertension, diabetes mellitus, atrial fibrillation, intravenous tPA, and successful recanalization, there was no statistically significant association between the presence of $\mathrm{CMB}$ and ICH (OR 1.19, 95\% CI 0.25-4.90, $\mathrm{p}=0.83$ ) or favorable clinical outcome at discharge (OR 1.25, $95 \%$ CI $0.38-4.01, \mathrm{p}=0.71)$. Results remained unchanged in subgroup analyses based on CMB location or burden.

Conclusion Our analysis indicates that the presence of CMBs is not significantly associated with poor clinical outcome or the risk of ICH following EVT.

Disclosures H. Saber: None. J. Saver: None. V. Szeder: None. M. Nour: None. K. Khatibi: None. L. Ponce Mejia: None. S. Tateshima: 2; C; Medtronic, Stryker, Cerenovus. G. Colby: 2; C; Medtronic, Stryker, MicroVention. N. Kaneko: None. R. Jahan: 2; C; Medtronic. G. Duckwiler: 2; C; Medtronic. D. Liebeskind: 2; C; Medtronic.

\section{P-017 EVALUATION OF RADIOFREQUENCY-INDUCED HEATING IN AN X-RAY AND MR-VISIBLE INTERVENTIONAL CATHETER AT $3.0 \mathrm{~T}$}

${ }^{1}$ B Kilbride* ${ }^{1} \mathrm{~J}$ Massachi, ${ }^{2} \mathrm{~S}$ Ahn, ${ }^{2} \mathrm{~K}$ Mueller, ${ }^{3} \mathrm{C}$ Jordan, ${ }^{4} \mathrm{~A}$ Losey, ${ }^{1} \mathrm{~A}$ Martin, ${ }^{1} \mathrm{~T}$ Moore, ${ }^{1} \mathrm{M}$ Wilson, 'S Hetts. 'Radiology and Biomedical Imaging, University of California San Francisco, San Francisco, CA; ${ }^{2}$ Siemens Medical Solutions, Malvern, PA; ${ }^{3}$ Texas AandM University, Houston, $T X_{i}^{4}$ Temple University, Philadelphia, PA

\subsection{6/neurintsurg-2021-SNIS.53}

Introduction Successful mechanical thrombectomy in the case of acute ischemic stroke can be inferred from the angiogram, and MRI information can provide insight regarding extent of cerebral infarct and whether further reperfusion therapy may increase the risk of hemorrhage. Recently, it has been shown that intra-procedural MRI can influence critical decision making to pursue further endovascular therapy. These decisions have been enabled by combined X-ray angiography MRI suites; all the while compatible tooling has lagged. Here, we have performed initial safety tests in vitro to validate the safety of a polymer-based guide catheter with in-wall X-ray and MR-visible markers.

Methods A guide catheter prototype was built using polymerbased filament in a catheter fabrication facility (Penumbra, Inc., Alameda, CA). Four circumferential marker bands were painted $2 \mathrm{~cm}$ from the distal tip. Markers were an epoxybased radiopaque ink (Creative Materials, Ayer, MA) doped with iron(III) oxide $\left(\mathrm{Fe}_{2} \mathrm{O}_{3}\right)$ nanoparticles of 20-40 nm diameter (Alfa Aesar, Tewksbury, MA). The device was then laminated with a multi-durometer thermoplastic jacket. Experiments were performed in a clinical biplane x-ray neuroangiography and 3.0 T MRI suite (Magnetom Skyra, Siemens Healthineers, AG, Forccheim, Germany).

The catheter was embedded into an acrylic phantom, per ASTM F2182-19e2. The head portion was made of a polyacrylamide gel and the body was filled with saline. The catheter extended $25 \mathrm{~cm}$ into the head and was laterally positioned $17 \mathrm{~cm}$ from the midline of the body and $6 \mathrm{~cm}$ from the midline of the head. Radiofrequency-induced heating of the prototype was assessed for worst-case heating as a function of insertion length. Heating directly adjacent to the catheter was measured using fluoroptic temperature probes (FOT Lab Kit with STF probes; LumaSense, Santa Clara, California). Two probes were embedded at the distal tip of the catheter and $10 \mathrm{~cm}$ proximal to the tip. Temperature was continuously measured over the course of 6 minutes: 2 minutes of baseline prior to imaging, 2 minutes of imaging using a True FISP sequence with a SAR of $4 \mathrm{~W} / \mathrm{kg}$, and 2 minutes of equilibration after imaging. The immersed length started at $95 \mathrm{~cm}$ and was shortened by $5 \mathrm{~cm}$ after each 6 -minute test until the immersed length was $60 \mathrm{~cm}$.

Results Maximum temperature and change in temperature were recorded. The largest temperature change occurred at $95 \mathrm{~cm}$, where the temperature rose by $0.45{ }^{\circ} \mathrm{C}$ and $0.70{ }^{\circ} \mathrm{C}$ at the device tip and $10 \mathrm{~cm}$ proximal to the tip, respectively. Over the entire testing period, the local temperature around the device tip and $10 \mathrm{~cm}$ proximal to the tip rose $1.48^{\circ} \mathrm{C}$ and $1.68^{\circ} \mathrm{C}$, respectively.

Conclusions Initial immersion tests suggest that the worst-case scenario for RF-induced heating of our guide catheter prototype occurs at $95 \mathrm{~cm}$. During the period of our tests, our prototype remained safely under the maximum permitted temperature rise of $+2^{\circ} \mathrm{C} / \mathrm{hr}$ of exposure. This study suggests that our guide catheter may be retained during an intra-procedural MRI without the safety risk of RF-induced device heating over time to the patient.

Disclosures B. Kilbride: None. J. Massachi: None. S. Ahn: None. K. Mueller: None. C. Jordan: None. A. Losey: None. A. Martin: None. T. Moore: None. M. Wilson: None. S. Hetts: None.

\section{P-018 VESSEL WALL IMAGING WITH MRI TO ASSESS ENDOTHELIAL WALL INJURY POST MECHANICAL THROMBECTOMY}

${ }^{1}$ R Mattay*, ${ }^{2} \mathrm{C}$ Favilla, ${ }^{1} \mathrm{~B}$ Pukenas, ${ }^{3} \mathrm{O}$ Choudhri, ${ }^{1} \mathrm{R}$ Hurst, ${ }^{1} \mathrm{~S}$ Nabavizadeh. ${ }^{1}$ Radiology, Hospital of the University of Pennsylvania, Philadelphia, PA; ${ }^{2}$ Neurology, Hospital of the University of Pennsylvania, Philadelphia, PA; ${ }^{3}$ Neurosurgery, Hospital of the University of Pennsylvania, Philadelphia, PA

\subsection{6/neurintsurg-2021-SNIS.54}

Purpose Mechanical thrombectomy using stent retrievers, aspiration catheters, or a combination of both are commonly used in practice to treat large vessel occlusion. Recent MR Vessel Wall Imaging (VWI) studies in patients status post thrombectomy in the acute and subacute phases have shown persistent increased vessel wall enhancement when compared to controls, which is likely representative of the endothelial damage to the vessel wall as shown on earlier histopathologic studies. In this study of 10 patients who underwent thrombectomy at our institution, we preliminarily explore the type and amount of vessel wall enhancement associated with different methods of thrombectomy and number of passes.

Materials and Methods 10 adult patients from 5/7/2019 to 9/ 9/2020 with occlusion of M1 segment who were admitted following mechanical thrombectomy underwent a $3 \mathrm{~T}$ brain MRI within 48 hours post-thrombectomy which included a 3D T1 black blood sequence before and after intravenous 